\title{
Social Media in Public Marketing: Facebook Pages of Regional Authorities
}

\author{
Pavel BACHMANN \\ University of Hradec Králové, Hradec Králové, Czech Republic \\ pavel.bachmanneuhk.cz
}

\begin{abstract}
Social media has become a new phenomenon of the society, which significantly affects not individuals only, but also organizations, including public institutions. An article aims on identification of current role of social media in public marketing. Specifically, it focuses on the sample of 13 regions of the Czech Republic and analyzes Facebook pages of its regional authorities. The content analysis concentrates on five blocks (out of seven original ones) of Kietzmann's honeycomb framework: identity, conversation, sharing, presence, and reputation. Findings confirmed that all the regions have their Facebook page set up, one third of regions react on citizen's request up to few minutes, the other one third up to one day. Regional authorities regularly publish its posts (11 posts per week in average) and share their own content, mainly.
\end{abstract}

Keywords: Social Media, Public Marketing, Regional Authorities, Content Analysis, Czech Republic.

\section{Introduction}

\subsection{Social media and its advent in a new millennium}

An advent of Internet and, consequently, the emergence of social media can be considered as one of the most important changes in society at the end of the last millennium and beginning of a new one. Today, in developed countries, the social media affect not only every life of human beings, but also majority of activities in business, public as well as nonprofit sector.

Social media serves as a technology which facilitates the dissemination and sharing of information. Today, the social media tools are mainly represented by platforms as Facebook, Twitter, YouTube, and others. It also includes communication tools such as Skype, or SecondLife, or professional tools as LinkedIn or ResearchGate. Although these social network platforms are often considered individual-level tools, they are just as useful at the agency, community, and policy level [7]. 


\section{Literature Review}

\subsection{Social Media in Public Marketing}

Social media have commonly begun to be used in a various sectors of public agenda. In education are social media, mainly Facebook, designated as "ideal host for a blended learning environment" [6], in social work can social media improve awareness of addicted people problems or better mental well-being of adolescents as young males who reported speaking to online friends regarding personal problems recorded statistically significantly higher levels of mental well-being [2], in healthcare the patients can benefit from the use of social media through medical education, better information, or receiving support [4]. Thus, as many public activities are taking place on social networks, the public marketing activities naturally follow.

\subsection{Use of Social Media in Czech Public Environment}

In European countries, including the Czech Republic, social media is becoming a common communication platform for politicians as well as for public organizations. While, traditionally, social mainstream site for politicians was Twitter, the attention of them is already moving on Facebook, today. Interestingly, the popularity among politicians on social networks differ a lot. While current President Miloš Zeman has 101,774 friends, the currently leaving Prime Minister Bohuslav Sobotka got only 16,583 friends. Remarkably, much higher attention received upcoming Prime Minister Andrej Babiš with more than 140,000 friends. It is not only because the political figures itself, but rather marketing is what matters here. Naturally, Facebook sites are common not only for politicians but also for public institutions. The Facebook page has set up The Office of the Government of the Czech Republic or Prague Castle as the seat of the Czech President. Presentation of public institutions is quite common not only for national organizations, but also for regional self-governing units, cities, and municipalities.

However, no in-depth research studies in this field exist to describe presentation of public institutions on social networks in Czech Republic, yet. Moreover, there is only a little evidence, worldwide. For these reasons, the present study aims to determine current role of social media in regional institutions, specifically regional authorities in the Czech Republic.

\section{Research Methods, Sample, and Data Gathering}

\subsection{Method, Social Media Indicators and Metrics}

The research study is based on the content analysis of Facebook pages. This kind of analysis conducted in online environment is a part of so called Internet mediated research [3]. Kietzmann's honeycomb framework [5] was used to investigate Facebook pages of regional authorities. This framework includes seven functional blocks of social media: identity, conversations, sharing, presence, relationships, 
reputation, and groups. Each block comprises (1) specific facet of social media user experience, and (2) its implication for firms. Kietzmann's approach is illustrated by Fig. 1.

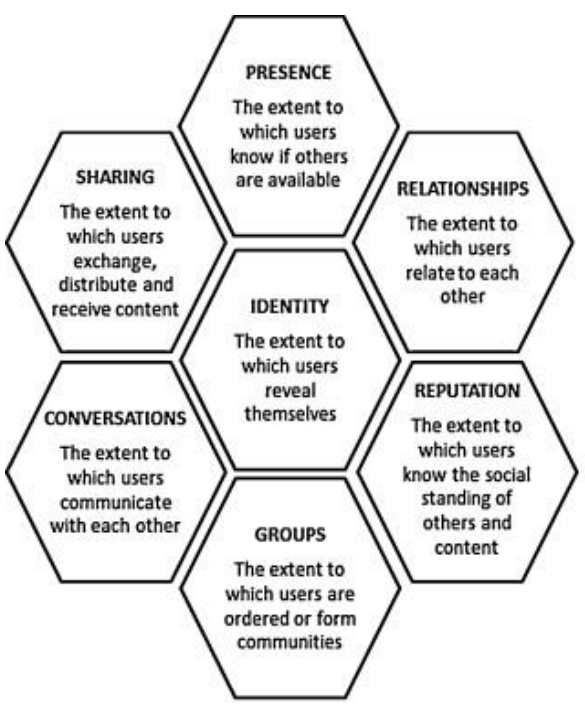

Social Media Functionality

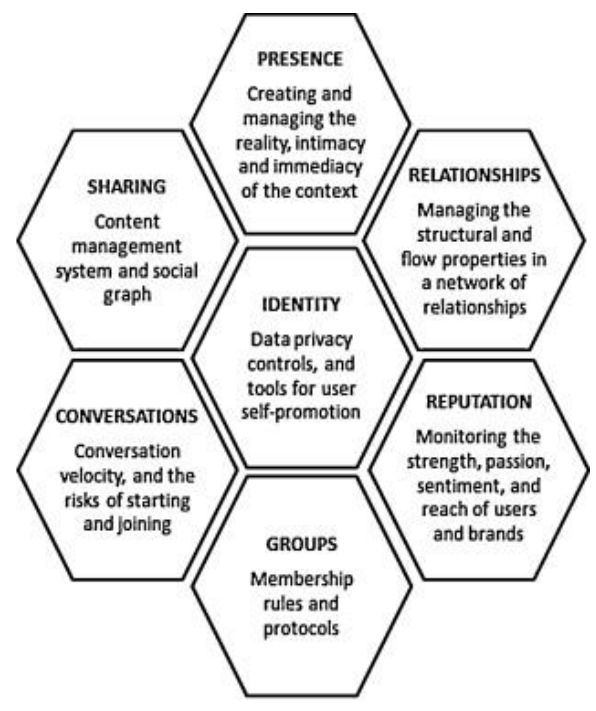

Implications of the Functionality

Fig. 1. Honeycomb framework of social media [5]

For the content analysis, only five out of the seven blocks were chosen for identification of situation in regional authorities Facebook page presentations: identity, conversation, sharing, presence, and reputation. The data of analysed facets of individual blocks were gathered during a seven-day period between Dec. 1, 2017 Dec. 7, 2017. Implications of the functionality of the pages are summarized in Table 1.

Table 1. Honeycomb blocks and their facets used in content analysis

\begin{tabular}{ll}
\hline Honeycomb block & Facets analysed \\
\hline Identity & Existence of Facebook page \\
& Page verification \\
& Facebook page reference on the website of regional authority \\
Conversation & Speed of reaction of regional authority (determined by Facebook) \\
Sharing & Number of shared posts (in \% of total posts) \\
& Number of posts shared from organizations administered by regional \\
& authority (in \% of total posts) \\
& Number of posts shared from other organizations (in \% of total posts) \\
\hline
\end{tabular}




\begin{tabular}{ll}
\hline Presence & Number of posts published in last 7 days \\
& Number of friends \\
& Number of followers \\
Reputation & Number of reviews \\
& Score of reviews \\
\hline
\end{tabular}

\subsection{Research Sample}

Research study focuses on regional authorities of the Czech Republic. According to the Act no. 129/2000 on Higher-level territorial self-governing units [1], the Czech Republic is divided in thirteen regions (kraje) and one capital city (hlavní město) with regional status of 1 January 2000. The capitol Prague was excluded from the sample due to several highly different facts: much higher tourist attention, almost doubled GDP per capita (547,096 CZK), as well as higher population (1,272,690 inhabitants) than in a majority of regions. The remaining thirteen regions were analyzed in detail. The main characteristics of all the regions researched are summarized in Table 2.

Table 2. List of regions included in the sample

\begin{tabular}{lccc}
\hline Name of the Region & $\begin{array}{c}\text { Population }(2011 \\
\text { census })\end{array}$ & $\begin{array}{c}\text { Area } \\
\left(\mathrm{km}^{2}\right)\end{array}$ & $\begin{array}{c}\text { GDP per capita } \\
(\mathrm{CZK})\end{array}$ \\
\hline Central Bohemian & $1,274,633$ & $11,014.97$ & 253,912 \\
South Bohemian & 637,460 & $10,056.79$ & 251,106 \\
Vysočina & 512,727 & $6,795.56$ & 234,530 \\
Plzeň & 574,694 & $7,560.93$ & 216,639 \\
Karlovy Vary & 310,245 & $3,314.46$ & 216,639 \\
Ústí nad Labem & 830,371 & $5,334.52$ & 229,146 \\
Liberec & 439,262 & $3,162.93$ & 229,146 \\
Hradec Králové & 555,683 & $4,758.54$ & 244,549 \\
Pardubice & 505,285 & 4,519 & 230,880 \\
Olomouc & 639,946 & $5,266.57$ & 211,467 \\
Moravian-Silesian & $1,236,028$ & $5,426.83$ & 222,638 \\
South Moravian & $1,169,788$ & $7,194.56$ & 254,684 \\
Zlín & 590,459 & $3,963.55$ & 222,885 \\
\hline
\end{tabular}

\section{$4 \quad$ Results}

\subsection{Identity}

All 13 researched regional authorities have set up their Facebook page. However, no regions have used a Facebook option for page verification in a form of blue or gray 
badge. On the other hand, the majority of regions (11 out of 13, 84.6\%) put Facebook page reference on their websites, which also can help to increase an authenticity of the page. Interestingly, as an example of page verification importance can serve the Vysočina region. The region has both official and unofficial Facebook page where that unofficial one is much more followed by Facebook visitors than the official one.

\subsection{Conversation}

Regional authorities reply on citizen's request variously. About one third of regions $(30.1 \%)$ replied in a few minutes after the request, one region replied in one hour ( 8.3 $\%)$. Another one third of regions replied in one day (30.1\%). In the remaining rest of regions the speed of reaction was not possible to identify. However, according to Facebook methodology of activation of this metrics, we can assume that these regions are replying more slowly than in one day. Complete results are summarized in Table 3.

Table 3. Conversation of regional authorities towards to public

\begin{tabular}{ll}
\hline Region & Speed of reaction of page administrators (measured by Facebook) \\
\hline Central Bohemian & in a few minutes \\
South Bohemian & in one day \\
Vysočina & in one day \\
Hradec Králové & in one day \\
Karlovy Vary & in a few minutes \\
Liberec & in one day \\
Moravian-Silesian & in a few minutes \\
Olomouc & n/a (reaction is too slow to be measured by Facebook) \\
Pardubice & in a few minutes \\
Plzeň & n/a (reaction is too slow to be measured by Facebook) \\
South Moravian & in one hour \\
Ústí & n/a (reaction is too slow to be measured by Facebook) \\
Zlín & n/a (reaction is too slow to be measured by Facebook)
\end{tabular}

\subsection{Sharing}

Regional authorities shared mainly their own posts. Majority of regions published own posts exclusively, the other $40 \%$ than published own posts mostly. Only Olomouc region shared majority of its posts from external sources. Among own resources were considered also sharing of regional TV broadcasts, regional magazines references, and broadcasting of the regional council meetings. Among external resources shared were either events of regional organizations as museums or schools, or regional/online mutations of the national newspapers. Complete results are summarized in Table 4. 
Table 4. Structure of posts shared on the Facebook page of Regional authority.

\begin{tabular}{lcrrr}
\hline & $\begin{array}{l}\text { Number of posts } \\
\text { published (last 7 } \\
\text { days) }\end{array}$ & $\begin{array}{l}\text { Own posts } \\
\text { shared } \\
\text { (in \%) }\end{array}$ & $\begin{array}{l}\text { Sharing of } \\
\text { agenda of } \\
\text { regional } \\
\text { organizations } \\
\text { (in \%) }\end{array}$ & $\begin{array}{l}\text { Sharing } \\
\text { from other } \\
\text { sources } \\
\text { (in \%) }\end{array}$ \\
Regional Authority & 20 & 65.0 & 30.0 & 5.0 \\
\hline Central Bohemian & 9 & 88.9 & 0.0 & 11.1 \\
South Bohemian & 10 & 100.0 & 0.0 & 0.0 \\
Vysočina & 8 & 100.0 & 0.0 & 0.0 \\
Hradec Králové & 17 & 100.0 & 0.0 & 0.0 \\
Karlovy Vary & 15 & 73.3 & 0.0 & 26.7 \\
Liberec & 10 & 100.0 & 0.0 & 0.0 \\
Moravian-Silesian & 19 & 36.8 & 0.0 & 63.2 \\
Olomouc & 10 & 50.0 & 20.0 & 30.0 \\
Pardubice & 9 & 77.8 & 0.0 & 22.2 \\
Plzeň & 5 & 100.0 & 0.0 & 0.0 \\
South Moravian & 4 & 75.0 & 25.0 & 0.0 \\
Ústí & 1 & 100.0 & 0.0 & 0.0 \\
Zlín & & & & \\
\hline
\end{tabular}

\subsection{Presence}

Regional authorities are present on the network when they are keeping contact with their citizens which can be expressed in the number of posts published. The regions published more than 10 posts per seven-day period in average. The most active were Central Bohemian, Liberec, and Olomouc regions with about 20 posts. The least active was Zlín region with only one post in last seven days.

Number of friends ranged from 862 in Zlín region up to 8,251 friends of Central Bohemian regional authority Facebook presentation. Interestingly, an official presentation of Vysočina region reached even higher number of friends - 9,913. Number of followers ranged in a very similarly to the number of friends. Complete results are summarized in Table 5.

Table 5. Posts, friends and followers on the Facebook page of the Regional authority

\begin{tabular}{lrrr}
\hline Regional Authority & Number of posts & Number of friends & Number of followers \\
\hline Central Bohemian & 20 & 8251 & 8258 \\
South Bohemian & 9 & 1080 & 1092 \\
Vysočina & 10 & $3370\left(9913^{*}\right)$ & $3378\left(9905^{*}\right)$ \\
Hradec Králové & 8 & 7664 & 7692
\end{tabular}




\begin{tabular}{lrrr} 
Karlovy Vary & 17 & 3822 & 3789 \\
Liberec & 19 & 4876 & 4746 \\
Moravian-Silesian & 10 & 8089 & 8148 \\
Olomouc & 19 & 1898 & 1890 \\
Pardubice & 10 & 6640 & 6623 \\
Plzeň & 9 & 2228 & 2221 \\
South Moravian & 5 & 2343 & 2386 \\
Ústí & 4 & 3935 & 3969 \\
Zlín & 1 & 862 & 889 \\
\hline
\end{tabular}

Note: Unofficial Facebook page

\subsection{Reputation}

Reputation of regional authorities can be expressed in several factors. Some of them as number of friends were already mentioned above in the text. The others as number of likes (or structure of reactions in general) could be a subject for another analysis. Therefore, regarding the reputation, the study focuses only on review score, which is given by page visitors that are, probably, also a region inhabitants.

An option to review Facebook page (or the region as it is) by the visitors was enabled by ten regions out of thirteen. A review score ranged from 3.9 in South Moravian region up to 4.9 in Vysočina region and 5.0 in South Bohemian region (only two reviews taken). Complete results are summarized in Table 6.

Table 6. Number of reviews and review score of Facebook pages of Regional authorities.

\begin{tabular}{lcc}
\hline Regional Authority & Number of reviews & Review score \\
\hline Central Bohemian & $\mathrm{n} / \mathrm{a}$ & $\mathrm{n} / \mathrm{a}$ \\
South Bohemian & 2 & 5.0 \\
Vysočina & 14 & 4.9 \\
Hradec Králové & 26 & 4.8 \\
Karlovy Vary & 7 & 4.7 \\
Liberec & 7 & 4.7 \\
Moravian-Silesian & 41 & 4.7 \\
Olomouc & 10 & 4.2 \\
Pardubice & $\mathrm{n} / \mathrm{a}$ & $\mathrm{n} / \mathrm{a}$ \\
Plzeň & 14 & 4.3 \\
South Moravian & 15 & 3.9 \\
Ústí & 24 & 4.4 \\
Zlín & $\mathrm{n} / \mathrm{a}$ & $\mathrm{n} / \mathrm{a}$ \\
\hline
\end{tabular}




\section{$5 \quad$ Discussion and Conclusion}

Research of regional authorities' Facebook pages revealed several interesting insights of current behavior of regions on the social networks:

- Regions mostly actively use their Facebook pages for public marketing, all of them have established a Facebook page. However, no regions have their Facebook presentation verified. Moreover, ability to search such regional page is limited on the network itself despite of the fact that 11 regions from 13 referred its Facebook page on their website.

- Regions usually react on the citizens requests promptly. $30 \%$ of them react even in a few minutes, another almost $40 \%$ in one hour or in one day.

- Regions publish mainly posts associated directly with the regional authority: it is either own text content (mainly pictures), or sharing regional magazines, records, or broadcasting.

- Reputation of regions can be considered as good one. It ranged from 3.9 to 5.0 with an average score of 4.6. However, three regional disabled the option to review the reputation, which could affect the final score negatively.

In general, there were not important differences among regions' activity found, with only the exception of Zlín region (lower number of posts as well as less friends and followers).

Despite the fact this study provides many interesting insights into the current use of social media for public marketing there are still many areas for consequent research. How the regions communicate with the visitors? How do they create a relationship with them? How they work with negative/positive comments? What is the structure of posts published? And many other issues.

\section{References}

1. Act no. 129/2000 Coll. (Law on Regions) on higher-level territorial self-governing units, https://ipfs.io/ipfs/QmXoypizjW3WknFiJnKLwHCnL72vedxjQkDDP1mXWo6uco/wiki/ Regions_of_the_Czech_Republic.html, last accessed 2017/10/10, (2000).

2. Best, P, Manktelow, R., Taylor, B. J.: Social Work and Social Media: Online HelpSeeking and the Mental Well-Being of Adolescent Males, The British Journal of Social Work, Volume 46, Issue 1, 1 January 2016, Pages 257-276, https://doi.org/10.1093/bjsw/bcu130, (2016).

3. Hewson, C.: Gathering data on the Internet. Qualitative approaches and possibilities for mixed methods research. The Oxford Handbook of Internet Psychology. Oxford University Press, (2007).

4. Househ, M.: The Use of Social Media in Healthcare: Organizational, Clinical, and Patient Perspectives. In: Enabling Health and Healthcare Through ICT: Available, Tailored and Closer edited by Karen L. Courtney, Omid Shabestari, Alex Kuo, p. 244, (2013).

5. Kietzmann J., H., Hermkens, K., McCarthy, I.,P., Silvestre, B., S.: Social media? Get serious! Understanding the functional building blocks of social media, In Business Horizons, Volume 54, Issue 3, 2011, pp. 241-251, https://doi.org/10.1016/j.bushor.2011.01.005, (2011). 
6. Keywords: Social media; Social networks; Web 2.0; User-generated content; Facebook; Twitter; LinkedIn; YouTube

7. McCarthy, J.: Blended learning environments: Using social networking sites to enhance the first year experience. Australasian Journal of Educational Technology, 26 (6), pp. 729 740, (2010).

8. Young, J.: The current status of social media use among nonprofit human service organizations: An exploratory study (Doctoral dissertation). Virginia Commonwealth University, Richmond, VA., https://digarchive.library.vcu.edu/handle/10156/3775, last access 2017/10/10. (2012). 